\title{
Infrared thermography and the numerical heat transfer analysis
}

(*) Faculty of Mechanical Engineering and Naval Architecture, University of Zagreb, Croatia.

\begin{abstract}
A method which enables the use of the data obtained by the IR thermography in the numerical heat transfer analysis has been developed. The method was tested on the model created for the determination of the local heat transfer coefficients on the extended surfaces. The temperature fields on the single annular and square fins were measured by means of an IR camera. The values of the temperatures were used directly as the input data in the mathematical model developed for the calculation and graphical interpretation of the local heat transfer coefficients. The model is based on the method of control volumes and is adopted to be used on a PC.
\end{abstract}

\section{Nomenclature}

$\begin{array}{lll}A & \text { surface } & \mathrm{m}^{2} \\ r & \text { radius } & \mathrm{m} \\ Q & \text { heat flow rate } & W \\ q_{\mathrm{i}} & \text { volumetric rate of heat generation } & \mathrm{Wm}^{-3} \\ t & \text { temperature } & \mathrm{K} \\ t_{\mathrm{o}} & \mathrm{K} \\ E, W, N, S, P & \text { grid points } & \\ e, w, n, s & \text { control volume faces } & \\ \lambda & \text { coefficient of heat conductivity } & \mathrm{Wm}^{-1} \mathrm{~K}^{-1} \\ \alpha & \text { heat transfer coefficient } & \mathrm{Wm}^{-2} \mathrm{~K}^{-1} \\ \Theta, \varphi & \text { angle } & \mathrm{rad}^{2}\end{array}$

\section{Introduction}

The determination of the real temperature field on the extended surface is a primary condition for the calculation of the local heat transfer coefficients. Former investigations $[3,4]$ show that the temperature field which occurs on the fin surface differs from this calculated analytically. The experiments done show that the temperature field on the fin is biased in the direction of the air flow and is not symmetrical. In previous experiments, mostly the thermocouples were used for measuring temperature and that was the reason for a long duration of the measurements. In the experiment presented thermographic measurements of the temperature field have been applied, and the data obtained were directly used in the mathematical model. The model enables the calculation of the local heat transfer coefficients on the fin surface. The method has been tested on the single annular fin placed in the wind tunnel. 


\section{Apparatus and procedure}

\subsection{Temperature field}

The temperature field on the fin surface was measured with the thermographic system AGA 680 standard. A single fin fastened perpendicularly on a tube and placed in the working section of the wind tunnel was in stationary state. The measurements were carried out with the air stream velocities between 0,5 and $5 \mathrm{~m} / \mathrm{s}$ and the fin base temperature between 30 and $80^{\circ} \mathrm{C}$. The obtained temperature field has been used as the source of the input data into the mathematical model made to calculate the local heat transfer coefficients on the fin surface. The experimental rig and the thermograms of single annular and square fins are shown on figures 1 and $A .^{*}$

\subsection{Local heat transfer coefficients}

For a thin annular fin being in a stationary state (figure 2) and made of high thermal conducting material, a differential equation describing the heat conduction through the fin can be given in the form:

$$
\left(\lambda \frac{\partial^{2} t}{\partial r^{2}}+\frac{\lambda}{r} \frac{\partial t}{\partial r}+\frac{\lambda}{r^{2}} \frac{\partial^{2} t}{\partial \varphi^{2}}\right)+\dot{q}_{i}=0
$$

The data obtained by the thermographic measurements represent boundary conditions for equation (1). To solve the equation (1), a numerical method of control volumes has been chosen [5]. The problem was treated as two-dimensional (figure 3) and after the discretization of the equation (1) we get:

$$
a_{P} t_{P}=a_{E} t_{E}+a_{W} t_{W}+a_{N} t_{N}+a_{S} t_{S}+b
$$

where

$$
\begin{gathered}
a_{E}=\frac{\lambda \Delta r z}{r_{e}(\delta \theta)_{e}} ; a_{N}=\frac{\lambda r_{n} \Delta \theta z}{(\delta r)_{n}} ; b=S_{c} \Delta V \\
a_{W}=\frac{\lambda \Delta r z}{r_{W}(\delta \theta)_{W}} ; a_{S}=\frac{\lambda r_{S} \Delta \theta z}{(\delta r)_{S}} \\
a_{P}=a_{E}+a_{W}+a_{N}+a_{S}+S_{P} \Delta V
\end{gathered}
$$

and 
$\Delta V$ control volume,

$S_{\mathrm{c}}$ is the constant part of the source term,

$S_{\mathrm{p}}$ is the dependant part of the source term.

If we write the equation (2) in the form:

$$
a_{E}\left(t_{P}-t_{E}\right)+a_{W}\left(t_{P}-t_{W}\right)+a_{N}\left(t_{P}-t_{N}\right)+a_{S}\left(t_{P}-t_{S}\right)=\Delta V\left(S_{C}+S_{P} t_{P}\right)
$$

after substitution, we obtain:

$$
Q_{e}+Q_{\mathrm{w}}+Q_{n}+Q_{S}=Q_{P}
$$

which represents the heat balance of the control volume. Considering the fact that the temperature field is known from the measurements, we can write the expression for the heat transferred from the fin in the form:

$$
Q_{P}=2 \alpha_{1} A_{P}\left(t_{P}-t_{0}\right)
$$

Inserting the equation (5) in equation (4), we obtain the expression for the local heat transfer coefficient:

$$
\alpha_{1}=\frac{Q_{e}+Q_{w}+Q_{n}+Q_{s}}{2 A_{P}\left(t_{P}-t_{0}\right)}
$$

Using the equations (2), (4), (5) and (6) the mathematical model for the calculation of the local heat transfer coefficients was made. The flow diagram of the mathematical model is shown on figure 4.

\section{Results}

The results obtained for one measurement are shown on figure 5 together with the measuring parameters.

The values of the local heat transfer coefficients include convection and radiation. From the local heat transfer coefficients, the average one has been calculated for the whole fin and the results compared with those given in [2]. The comparison shows good mutual accordance (figure 6) which leads to the conclusion that the thermographic method can be successfully applied to the analysis of the temperature fields and the heat transfer from the fin surface. 


\section{http://dx.doi.org/10.21611/qirt.1992.018}

\section{Conclusion}

Thermographic method enables a quick determination of the real temperature field on the single fin surface. Supplied with the adequate software it enables the calculation of the heat transfer parameters such as the local and average heat transfer coefficients and the heat transferred from the fin. On the basis of such analysis the coefficient of performance for various fin shapes can be easily done. The graphical interpretation of one temperature field and the field of local heat transfer coefficients are given on figure 7. It can be concluded that the thermographic measurements of temperature fields can be successfully used as the basis of many research works dealing with the heat transfer problems, specially when the numerical analysis is applied.

\section{REFERENCES}

[1] KERN (D.Q) and KRAUS (A.D.). - Extended surfaces heat transfer. Mc Graw-Hill Book Co., New York, 1977.

[2] KRISCHER (O.) und KAST (W.). - Warmeubertragung und Warmespanungen bei Rippenrohren. VDI-Verlag GmbH, Dusseldorf, 1959.

[3] JONES (T.V.) and RUSSEL (C.M.B.). - Local heat transfer coefficient on finned tubes. ASME HTD, Vol.21, Winter Annual Meeting 1981.

[4] WONG (P.W.). - Mass and heat transfer from circular finned cylinders. J.I.H.V.E., April, 1966.

[5] PATANKAR (S.V.). - Numerical heat transfer and fluid flow. Hemisphere Publishing Co.,Mc Graw-Hill Book Co.

[6] SVAIC (S.). - Thermographic analysis of haeat transfer from annular fin. Faculty for Mechanical Engineering and Naval Architecture Zagreb, Thesis, 1990.

[7] SVAIC (S.). - Annular fin efficiencies from thermographic measurements of temperature distribution. XVIII International Congress of Refrigeration, Montreal, 1991.

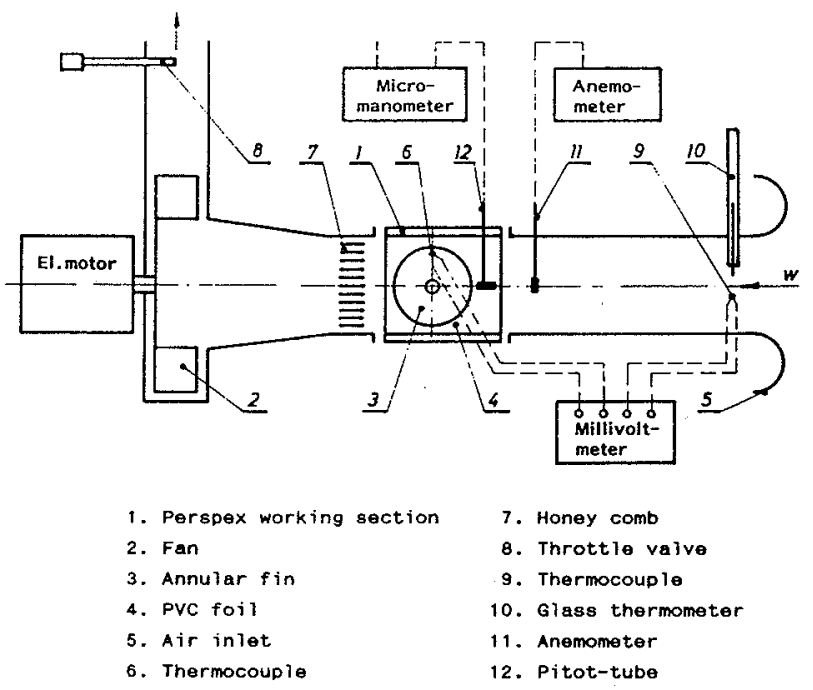

Fig. 1. - Experimental rig 


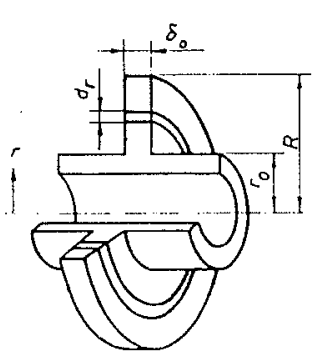

Fig. 2. - Annular fin
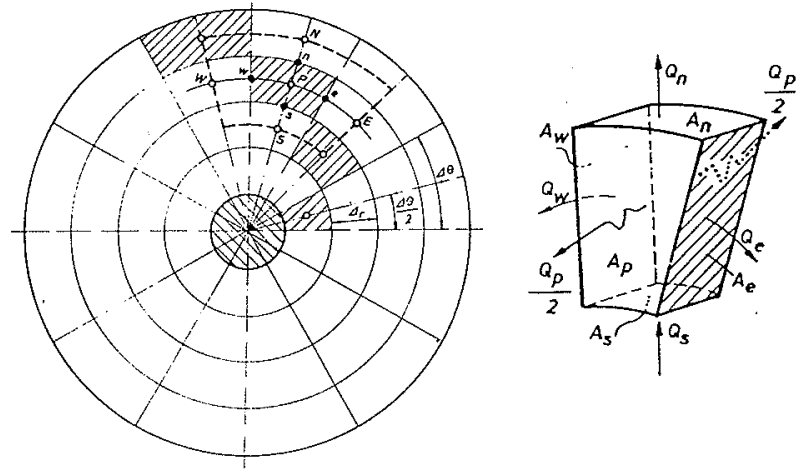

Fig. 3. - Control volumes

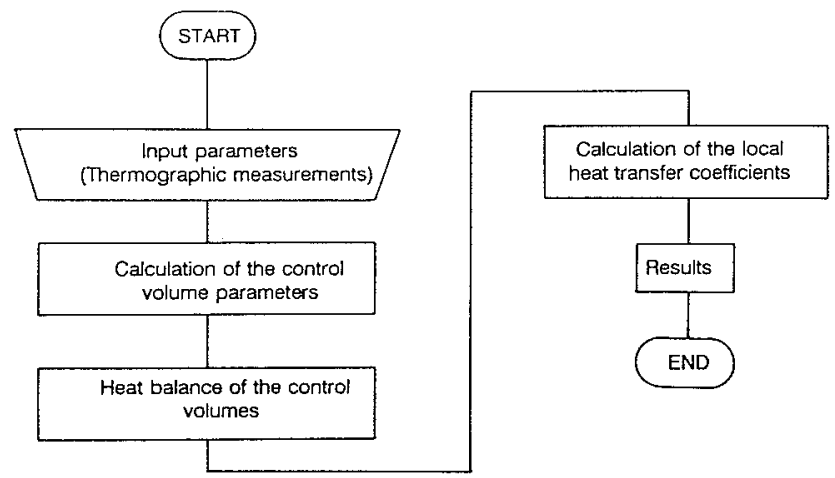

Fig. 4. - Flow diagram
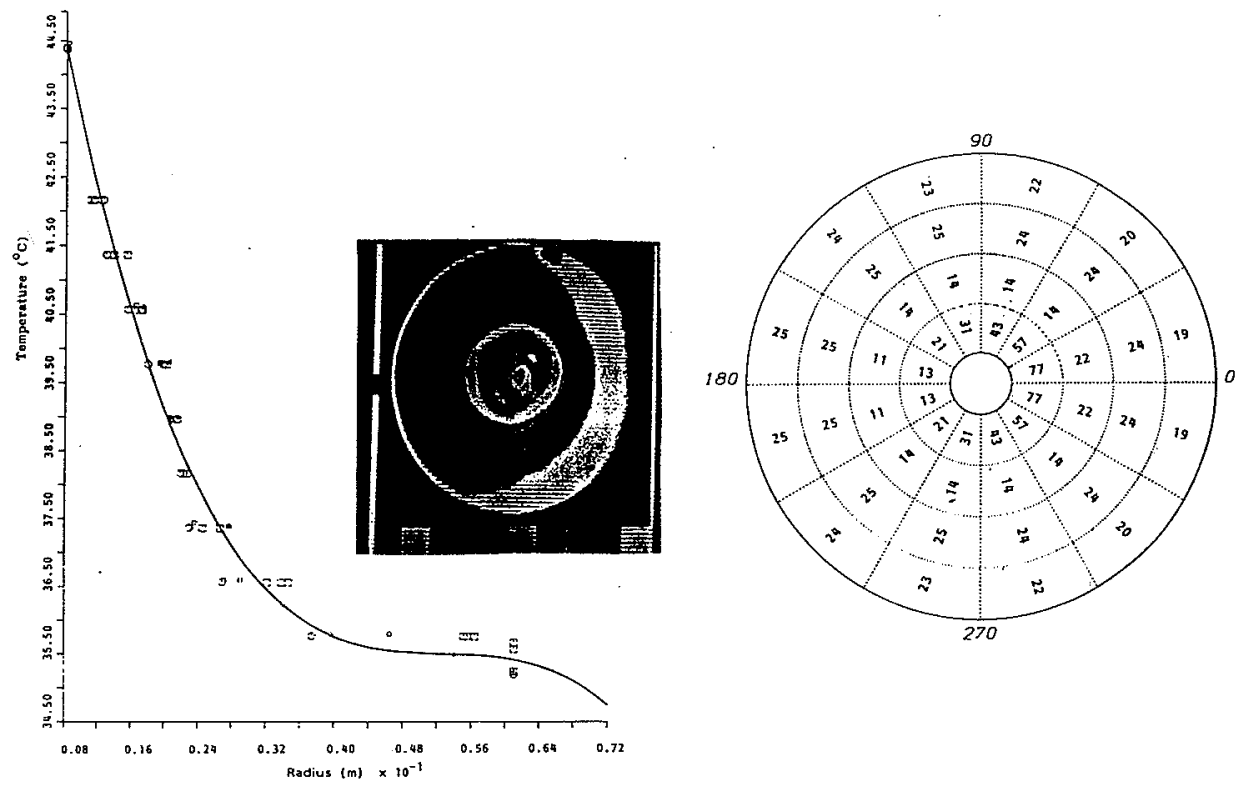

Fig. 5. - Thermogram, function of temperature distribution and the local heat transfer coefficients 
http://dx.doi.org/10.21611/qirt.1992.018

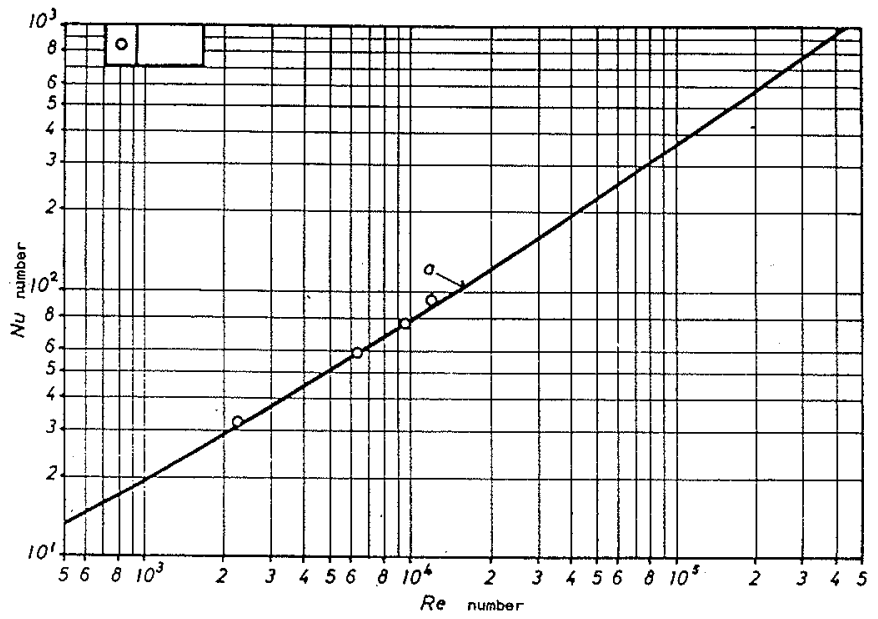

Fig. 6. - Average heat transfer coefficients (results obtained from the four measurements and compared with those given in $/ 2 /$ )
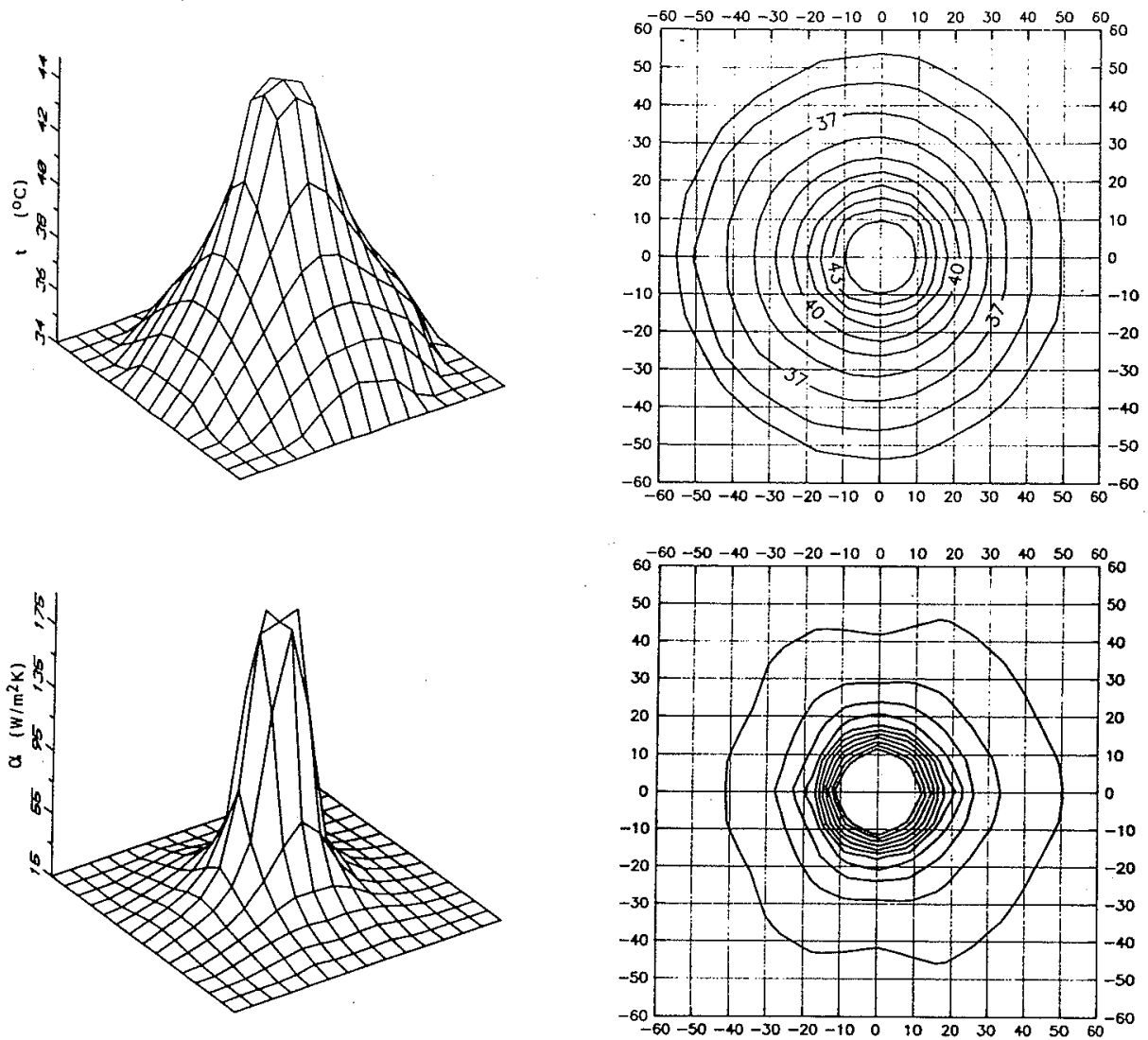

Fig. 7. - Temperature field and the local heat transfer coefficients 